\title{
Comorbidity Type and Health Care Costs in Type 2 Diabetes: A Retrospective Claims Database Analysis
}

Pei-Jung Lin (D) · Elle Pope $\cdot$ Fang Liz Zhou

Received: June 5, 2018 / Published online: August 10, 2018

(C) The Author(s) 2018

\begin{abstract}
Introduction: Previous studies suggest that the type and combination of comorbidities may impact diabetes care, but their cost implications are less clear. This study characterized how diabetes patients' health care utilization and costs may vary according to comorbidity type classified on the basis of the Piette and Kerr framework.

Methods: We conducted a retrospective observational study of privately insured US adults newly diagnosed with type 2 diabetes ( $n=138,466)$ using the 2014-2016 Optum Clinformatics $^{\circledR}$ Data Mart. Diabetes patients were classified into five mutually exclusive comorbidity groups: concordant only,
\end{abstract}

Enhanced digital features To view enhanced digital features for this article go to https://doi.org/10.6084/ m9.figshare.6854684.

Electronic supplementary material The online version of this article (https://doi.org/10.1007/s13300018-0477-2) contains supplementary material, which is available to authorized users.

P.-J. Lin $(\bowtie) \cdot$ E. Pope

Center for the Evaluation of Value and Risk in Health, Institute for Clinical Research and Health Policy Studies, Tufts Medical Center, Boston, MA, USA

e-mail: plin@tuftsmedicalcenter.org

F. L. Zhou

Real World Evidence and Clinical Outcomes, Sanofi, Bridgewater, NJ, USA discordant only, both concordant and discordant, any dominant, and none. We estimated average health care costs of each comorbidity group by using generalized linear models, adjusting for patient demographics, region, insurance type, and prior-year costs.

Results: Most type 2 diabetes patients had discordant conditions only (27\%), dominant conditions $(25 \%)$, or both concordant and discordant conditions (24\%); 7\% had concordant conditions only. In adjusted analyses, comorbidities were significantly associated with higher health care costs $(p<0.0001)$ and the magnitude of the association varied with comorbidity type. Diabetes patients with dominant comorbidities incurred substantially higher costs $(\$ 38,168)$ compared with individuals with both concordant and discordant conditions $(\$ 20,401)$, discordant conditions only (\$9173), concordant conditions only (\$9000), and no comorbidities (\$3365). More than half of the total costs in our sample (53\%) were attributable to $25 \%$ of diabetes patients who had dominant comorbidities.

Conclusions: Diabetes patients with both concordant and discordant conditions and with clinically dominant conditions incurred substantially higher health costs than other diabetes patients. Our findings suggest that diabetes management programs must explicitly address concordant, discordant, and dominant conditions because patients may have distinctly different health care needs and utilization 
patterns depending on their comorbidity profiles. The Piette and Kerr framework may serve as a screening tool to identify high-need, highcost diabetes patients and suggest targets for tailored interventions.

Funding: Sanofi.

Keywords: Comorbidity; Health care costs; Health care utilization; Risk adjustment; Type 2 diabetes

\section{INTRODUCTION}

The type and combination, not just the increased number, of comorbidities may affect access to and quality of care in type 2 diabetes [1-12]. Comorbid conditions that share similar pathophysiologic effects with diabetes (e.g., cardiovascular diseases) naturally may be part of the disease management plan, and treatment of such types of comorbidities could also improve diabetes outcomes [3-5]. In contrast, a higher burden of severe, clinically dominant comorbidities (e.g., cancer) or conditions that are considered unrelated to diabetes (e.g., lung diseases) may shift disease management priority away from diabetes, possibly as a result of competing demands $[2-5,9-11,13]$.

To characterize the effects of different comorbidities in diabetes, Piette and Kerr classified comorbid illnesses as concordant (conditions that share similar pathophysiologic risk or disease management plan as diabetes), discordant (conditions with pathophysiologic risk and disease management plan that are not directly related to diabetes), and dominant (severe conditions that may limit life expectancy or require extensive medical treatment likely to eclipse diabetes management) [1, 2]. This framework, reflecting the nature of the comorbidity, has been used widely in diabetes research and beyond [3-6, 10-12, 14]. Although studies have reported on the relationship between comorbidity type and diabetes quality of care $[3,4,6,7,10-12]$, whether a certain type of comorbidity (concordant, discordant, or dominant) may be associated with higher health care utilization and costs remains unclear. Diabetes patients with complex, severe comorbid conditions may use substantial health care services, but how their costs compare with diabetes patients who have other types of comorbidities has yet to be quantified.

Studies have shown that individuals with type 2 diabetes may incur higher (more than two times greater) health care costs compared to those without diabetes [15]. Further, among people with the same chronic condition, such as depression [16] and cardiovascular disease [17], health care costs may be substantially higher for patients with diabetes than those without. Given the rising economic burden of diabetes [15], assessments of comorbidity cost impacts in diabetes will help managed care organizations evaluate the disease burden in particular patient subgroups and plan resource allocation accordingly [18]. As payers, providers, and policymakers consider various approaches to containing diabetes costs, it is crucial to identify high-cost patients and implement tailored care management programs to serve different segments of the population [19].

The objective of this study was to characterize how type 2 diabetes patients' health care utilization and costs may vary according to the type of comorbidities based on the Piette and Kerr framework $[1,2]$. We examined the relationship between comorbidity type and health care utilization and costs among adults newly diagnosed with type 2 diabetes in a large, privately insured US population. Unlike previous research that has focused on comorbidity counts or individual comorbid conditions, our study assessed the effects of comorbidity type based on a clinically meaningful classification. This information is important because it provides insight into the interactions between diabetes and comorbidities, which may suggest targets for tailored interventions to improve the efficiency of diabetes care.

\section{METHODS}

\section{Data and Sample}

We used data from the 2014-2016 Optum Clinformatics $^{\circledR}$ Data Mart, which collects 
administrative claims for individuals enrolled in commercial health insurance plans in the USA. The database contains individual-level, deidentified health care information on patient enrollment, medical and pharmaceutical claims, and lab results data. Our sample consisted of privately insured individuals aged 18 years or more who were newly diagnosed with type 2 diabetes (ICD-9-CM: 250.x0 and 250.x2; ICD-10-CM: E11.x) between January 1, 2015, and December 31, 2015 (the diagnosis date was identified as the "index date"). We defined newly diagnosed patients as individuals who did not have any type 2 diabetes diagnosis or use any diabetes medications during the 12 months prior to the index date. Patients with any diagnosis of type 1 diabetes (ICD-9-CM: 250.x1 and 250.x3; ICD-10-CM: E10.x), gestational diabetes (ICD-9-CM: 648.8; ICD-10-CM: O24.x), or secondary diabetes (ICD-9-CM: 249; ICD-10-CM: E08.x) during the study period were excluded. All subjects were required to be continuously enrolled for at least 12 months prior to and following the index date. The Tufts Medical Center/Tufts University Health Sciences IRB reviewed this study and determined that it is exempt. This article does not contain any studies with human participants or animals performed by any of the authors.

\section{Measures}

Primary outcomes of interest were health care utilization and costs (including ambulatory, inpatient, ED, and prescriptions) during the year following a type 2 diabetes diagnosis. Ambulatory care in this analysis included physician office visits and hospital outpatient clinics. We measured comorbidities at baseline (i.e., during the 12 months prior to the index date) using ICD-9-CM diagnosis codes recorded in medical claims. We categorized conditions into five mutually exclusive groups as defined by the Piette and Kerr framework: concordant only, discordant only, both concordant and discordant, any dominant, and none (Appendix 1) $[1,2]$. Other baseline patient characteristics included age, gender, race, region, insurance type, and total health care costs during the year prior to the type 2 diabetes diagnosis.

\section{Analysis}

In descriptive analyses, we used chi-square tests to compare patient characteristics and unadjusted health care utilization and costs across comorbidity groups. In adjusted analyses, we estimated mean total health care costs and ambulatory costs by comorbidity group, using generalized linear models (GLMs) with a gamma distribution and a log link. GLM fitted values were generated by using the recycled predictions method [20,21]. Because only a subset of patients used inpatient, ED, and prescription drugs, we performed two-part models to estimate each cost component. The first part used logistic regression to predict the probability of incurring any costs. The second part estimated mean costs among those with at least some costs, using the same GLM structure described above. Combining results from these two model components yielded population cost estimates. We started with a parsimonious model, adjusting for comorbidity type, age, sex, and race. The fully adjusted model also included region, insurance type, and total health care costs at baseline. Finally, we examined the distribution of health care spending by calculating the proportion of total costs attributable to each comorbidity group.

\section{RESULTS}

\section{Sample Characteristics}

Our sample included 138,466 patients newly diagnosed with type 2 diabetes, with a mean age of 64 years; $50 \%$ were female and $60 \%$ were non-Hispanic whites (Table 1). The majority of patients $(83 \%)$ had at least one comorbidity. Most (27\%) had discordant conditions only, followed by dominant (25\%) and both concordant and discordant conditions (24\%); 7\% had concordant conditions only. Patients with type 2 diabetes who had dominant, concordant only, 
Table 1 Sample characteristics by comorbidity type

\begin{tabular}{|c|c|c|c|c|c|c|c|}
\hline Characteristics & Overall & $\begin{array}{l}\text { Concordant } \\
\text { only }\end{array}$ & $\begin{array}{l}\text { Discordant } \\
\text { only }\end{array}$ & Both & Dominant & None & $p$ value \\
\hline$N(\%)$ & $\begin{array}{r}138,466 \\
(100 \%)\end{array}$ & $9064(6.5 \%)$ & $\begin{array}{l}37,813 \\
\quad(27.3 \%)\end{array}$ & $\begin{array}{l}33,360 \\
\quad(24.1 \%)\end{array}$ & $\begin{array}{l}34,713 \\
(25.1 \%)\end{array}$ & $\begin{array}{l}23,516 \\
\quad(17.0 \%)\end{array}$ & \\
\hline Female & $50.6 \%$ & $36.9 \%$ & $55.4 \%$ & $47.7 \%$ & $55.9 \%$ & $44.7 \%$ & $<0.0001$ \\
\hline Age, mean (s.d.) & $64.4(14.7)$ & $68.3(12.9)$ & $58.9(14.1)$ & $68.6(12.4)$ & $69.6(13.7)$ & $\begin{array}{l}58.2 \\
(15.1)\end{array}$ & $<0.0001$ \\
\hline $18-34$ & $3.4 \%$ & $1.6 \%$ & $5.3 \%$ & $1.2 \%$ & $1.6 \%$ & $6.7 \%$ & $<0.0001$ \\
\hline $35-44$ & $7.4 \%$ & $3.8 \%$ & $11.2 \%$ & $3.4 \%$ & $4.1 \%$ & $13.3 \%$ & \\
\hline $45-54$ & $14.4 \%$ & $9.9 \%$ & $20.6 \%$ & $9.3 \%$ & $9.4 \%$ & $20.9 \%$ & \\
\hline $55-64$ & $18.1 \%$ & $15.5 \%$ & $22.6 \%$ & $16.8 \%$ & $14.7 \%$ & $18.6 \%$ & \\
\hline $65+$ & $56.7 \%$ & $69.2 \%$ & $40.2 \%$ & $69.3 \%$ & $70.2 \%$ & $40.4 \%$ & \\
\hline \multicolumn{8}{|l|}{ Race } \\
\hline Caucasian & $59.4 \%$ & $55.6 \%$ & $59.5 \%$ & $63.3 \%$ & $62.2 \%$ & $51.1 \%$ & $<0.0001$ \\
\hline Hispanic & $13.2 \%$ & $13.3 \%$ & $13.7 \%$ & $10.2 \%$ & $11.9 \%$ & $18.4 \%$ & \\
\hline Black & $10.6 \%$ & $9.2 \%$ & $11.4 \%$ & $10.3 \%$ & $10.2 \%$ & $10.6 \%$ & \\
\hline Asian & $4.8 \%$ & $5.3 \%$ & $4.7 \%$ & $3.7 \%$ & $4.1 \%$ & $7.5 \%$ & \\
\hline Missing & $12.0 \%$ & $16.6 \%$ & $10.6 \%$ & $12.5 \%$ & $11.6 \%$ & $12.5 \%$ & \\
\hline \multicolumn{8}{|l|}{ Health insurance type } \\
\hline Medicare & $59.5 \%$ & $68.3 \%$ & $44.9 \%$ & $72.9 \%$ & $73.6 \%$ & $39.7 \%$ & $<0.0001$ \\
\hline Commercial & $40.5 \%$ & $31.7 \%$ & $55.1 \%$ & $27.1 \%$ & $26.4 \%$ & $60.3 \%$ & \\
\hline \multicolumn{8}{|l|}{ Region } \\
\hline South & $40.7 \%$ & $38.2 \%$ & $42.1 \%$ & $39.8 \%$ & $39.8 \%$ & $41.9 \%$ & $<0.0001$ \\
\hline Midwest & $19.2 \%$ & $16.2 \%$ & $19.9 \%$ & $19.6 \%$ & $19.2 \%$ & $18.4 \%$ & \\
\hline Northeast & $20.0 \%$ & $19.7 \%$ & $19 \%$ & $21.7 \%$ & $22.3 \%$ & $15.7 \%$ & \\
\hline West & $20.1 \%$ & $25.7 \%$ & $18.9 \%$ & $18.7 \%$ & $18.6 \%$ & $23.9 \%$ & \\
\hline Missing & $0.2 \%$ & $0.3 \%$ & $0.1 \%$ & $0.1 \%$ & $0.1 \%$ & $0.3 \%$ & \\
\hline $\begin{array}{l}\text { Baseline total health care } \\
\text { costs, mean (s.d.) }\end{array}$ & $\begin{array}{l}\$ 11,499 \\
\quad(\$ 33,460)\end{array}$ & $\begin{array}{l}\$ 4139 \\
\quad(\$ 11,071)\end{array}$ & $\begin{array}{l}\$ 6132 \\
\quad(\$ 13,588)\end{array}$ & $\begin{array}{l}\$ 13,278 \\
\quad(\$ 29,736)\end{array}$ & $\begin{array}{l}\$ 24,147 \\
\quad \$ 55,571)\end{array}$ & $\begin{array}{l}\$ 1772 \\
\quad(\$ 5738)\end{array}$ & $<0.0001$ \\
\hline
\end{tabular}

and both concordant and discordant comorbidities were older than other groups $(p<0.0001)$.

\section{Unadjusted Health Care Utilization and Costs by Comorbidity Type}

Average health care costs during the year following a new diabetes diagnosis were roughly 
Table 2 Unadjusted health care utilization and costs by comorbidity type

\begin{tabular}{|c|c|c|c|c|c|c|c|}
\hline & Overall & $\begin{array}{l}\text { Concordant } \\
\text { only }\end{array}$ & $\begin{array}{l}\text { Discordant } \\
\text { only }\end{array}$ & Both & Dominant & None & $p$ value \\
\hline$N(\%)$ & $\begin{array}{l}138,466 \\
(100 \%)\end{array}$ & $9064(6.5 \%)$ & $\begin{array}{l}37,813 \\
\quad(27.3 \%)\end{array}$ & $\begin{array}{l}33,360 \\
\quad(24.1 \%)\end{array}$ & $\begin{array}{l}34,713 \\
\quad(25.1 \%)\end{array}$ & $\begin{array}{l}23,516 \\
\quad(17.0 \%)\end{array}$ & \\
\hline $\begin{array}{l}\text { Total health care costs } \\
\text { (s.d.) }\end{array}$ & $\begin{array}{l}\$ 17,950 \\
\quad(\$ 46,175)\end{array}$ & $\begin{array}{l}\$ 8625 \\
\quad(\$ 45,624)\end{array}$ & $\begin{array}{l}\$ 9080 \\
\quad(\$ 16,240)\end{array}$ & $\begin{array}{l}\$ 20,070 \\
\quad(\$ 34,081)\end{array}$ & $\begin{array}{l}\$ 37,986 \\
\quad(\$ 76,587)\end{array}$ & $\begin{array}{l}\$ 3224 \\
\quad(\$ 6781)\end{array}$ & $<0.0001$ \\
\hline \multicolumn{8}{|l|}{ Inpatient } \\
\hline Average costs (s.d.) & $\begin{array}{l}\$ 5264 \\
\quad(\$ 23,602)\end{array}$ & $\begin{array}{l}\$ 2070 \\
\quad(\$ 9827)\end{array}$ & $\begin{array}{l}\$ 1560 \\
\quad(\$ 8705)\end{array}$ & $\begin{array}{l}\$ 6659 \\
\quad(\$ 22,881)\end{array}$ & $\begin{array}{l}\$ 12,185 \\
\quad(\$ 38,988)\end{array}$ & $\begin{array}{l}\$ 258 \\
\quad(\$ 3137)\end{array}$ & $<0.0001$ \\
\hline $\begin{array}{l}\text { \# of hospitalized } \\
\text { patients (\%) }\end{array}$ & $\begin{array}{l}24,997 \\
\quad(18.1 \%)\end{array}$ & $950(10.5 \%)$ & $2863(7.6 \%)$ & $\begin{array}{l}8568 \\
\quad(25.7 \%)\end{array}$ & $\begin{array}{l}12,236 \\
(35.2 \%)\end{array}$ & $\begin{array}{l}380 \\
\quad(1.6 \%)\end{array}$ & $<0.0001$ \\
\hline $\begin{array}{l}\text { \# of hospitalizations, } \\
\text { mean (s.d.) }\end{array}$ & $0.35(1.15)$ & $0.12(0.40)$ & $0.10(0.42)$ & $0.43(1.02)$ & $0.83(1.91)$ & $\begin{array}{l}0.02 \\
\quad(0.14)\end{array}$ & $<0.0001$ \\
\hline $\begin{array}{l}\text { Length of stay, mean } \\
\text { (s.d.) }\end{array}$ & $8.04(13.66)$ & $5.08(6.03)$ & $5.15(5.16)$ & $6.70(9.88)$ & $\begin{array}{l}10.02 \\
\quad(17.18)\end{array}$ & $\begin{array}{l}4.10 \\
\quad(3.74)\end{array}$ & $<0.0001$ \\
\hline \multicolumn{8}{|l|}{ Ambulatory } \\
\hline Average costs (s.d.) & $\begin{array}{l}\$ 9775 \\
\quad(\$ 32,916)\end{array}$ & $\begin{array}{l}\$ 5142 \\
\quad(\$ 44,038)\end{array}$ & $\begin{array}{l}\$ 5427 \\
\quad(\$ 10,217)\end{array}$ & $\begin{array}{l}\$ 10,032 \\
(\$ 18,548)\end{array}$ & $\begin{array}{l}\$ 20,614 \\
\quad(\$ 56,317)\end{array}$ & $\begin{array}{l}\$ 2187 \\
\quad(\$ 4990)\end{array}$ & $<0.0001$ \\
\hline \# of patients (\%) & $\begin{array}{l}138,178 \\
(99.8 \%)\end{array}$ & $9018(99.5 \%)$ & $\begin{array}{l}37,754 \\
\quad(99.8 \%)\end{array}$ & $\begin{array}{l}33,315 \\
\quad(99.9 \%)\end{array}$ & $\begin{array}{l}34,668 \\
\quad(99.9 \%)\end{array}$ & $\begin{array}{l}23,423 \\
\quad(99.6 \%)\end{array}$ & $<0.0001$ \\
\hline $\begin{array}{l}\text { \# of ambulatory visits, } \\
\text { mean (s.d.) }\end{array}$ & $\begin{array}{l}23.42 \\
\quad(28.17)\end{array}$ & $12.35(12.95)$ & $\begin{array}{l}16.79 \\
(15.30)\end{array}$ & $\begin{array}{l}27.66 \\
(24.96)\end{array}$ & $\begin{array}{l}40.03 \\
\quad(41.15)\end{array}$ & $\begin{array}{l}7.82 \\
(7.43)\end{array}$ & $<0.0001$ \\
\hline \multicolumn{8}{|l|}{ Emergency department } \\
\hline Average costs (s.d.) & $\begin{array}{l}\$ 677 \\
\quad(\$ 3055)\end{array}$ & $\begin{array}{l}\$ 224 \\
\quad(\$ 1253)\end{array}$ & $\begin{array}{l}\$ 261 \\
\quad(\$ 1401)\end{array}$ & $\begin{array}{l}\$ 906 \\
\quad(\$ 3147)\end{array}$ & $\begin{array}{l}\$ 1449 \\
\quad(\$ 4888)\end{array}$ & $\begin{array}{l}\$ 56 \\
\quad(\$ 433)\end{array}$ & $<0.0001$ \\
\hline$\#$ of patients (\%) & $\begin{array}{l}34,486 \\
\quad(24.9 \%)\end{array}$ & $1198(13.2 \%)$ & $\begin{array}{l}6517 \\
\quad(17.2 \%)\end{array}$ & $\begin{array}{l}11,149 \\
(33.4 \%)\end{array}$ & $\begin{array}{l}14,095 \\
\quad(40.6 \%)\end{array}$ & $\begin{array}{l}1527 \\
(6.5 \%)\end{array}$ & $<0.0001$ \\
\hline $\begin{array}{l}\text { \# of ED visits, mean } \\
\text { (s.d.) }\end{array}$ & $1.12(3.99)$ & $0.37(1.31)$ & $0.71(2.71)$ & $1.43(3.76)$ & $2.12(6.24)$ & $\begin{array}{l}0.17 \\
\quad(0.92)\end{array}$ & $<0.0001$ \\
\hline \multicolumn{8}{|l|}{ Prescription drugs } \\
\hline Average costs (s.d.) & $\begin{array}{l}\$ 2234 \\
\quad(\$ 8034)\end{array}$ & $\begin{array}{l}\$ 1189 \\
\quad(\$ 2757)\end{array}$ & $\begin{array}{l}\$ 1832 \\
\quad(\$ 6475)\end{array}$ & $\begin{array}{l}\$ 2473 \\
\quad(\$ 7078)\end{array}$ & $\begin{array}{l}\$ 3738 \\
\quad(\$ 12,365)\end{array}$ & $\begin{array}{l}\$ 723 \\
\quad(\$ 2560)\end{array}$ & $<0.0001$ \\
\hline \# of patients (\%) & $\begin{array}{l}129,241 \\
\quad(93.3 \%)\end{array}$ & $7945(87.7 \%)$ & $\begin{array}{l}35,753 \\
\quad(94.6 \%)\end{array}$ & $\begin{array}{l}31,915 \\
\quad(95.7 \%)\end{array}$ & $\begin{array}{l}33,387 \\
\quad(96.2 \%)\end{array}$ & $\begin{array}{l}20,241 \\
\quad(86.1 \%)\end{array}$ & $<0.0001$ \\
\hline $\begin{array}{l}\text { \# of prescription fills, } \\
\text { mean (s.d.) }\end{array}$ & $41.3(46.1)$ & $26.2(25.3)$ & $30.0(28.9)$ & $50.7(43.9)$ & $66.0(63.4)$ & $\begin{array}{l}15.5 \\
\quad(16.5)\end{array}$ & $<0.0001$ \\
\hline
\end{tabular}


$\$ 18,000$ per person (Table 2 ). On average, diabetes patients with dominant comorbidities incurred the highest health care costs $(\$ 37,986)$, followed by those with both concordant and discordant conditions $(\$ 20,070)$, discordant conditions only (\$9080), and concordant conditions only (\$8625), whereas patients with diabetes only and no other comorbidities had the lowest costs $(\$ 3224)(p<0.0001)$. Higher proportions of diabetes patients with dominant comorbidities and both concordant and discordant conditions were hospitalized, compared with other comorbidity groups $(p<0.0001)$; those patients also had more ambulatory visits, ED visits, and more prescription fills $(p<0.0001)$.

\section{Regression Analysis and Predicted Mean Costs by Care Component and by Comorbidity Type}

In adjusted analyses, comorbidities were significantly associated with higher total health care costs $(p<0.0001)$ and the magnitude of the association varied with comorbidity type (Appendix 2). These effects remained statistically significant after adjusting for health insurance type, region, and baseline costs in addition to demographic characteristics (Model 2). Mean health care costs estimated by the fully adjusted model were the highest for diabetes patients with dominant comorbidities $(\$ 38,168)-87 \%$ greater than diabetes patients with both concordant and discordant conditions $(\$ 20,401)$, $316 \%$ greater than those with discordant conditions only (\$9173), and 324\% greater than those with concordant conditions only (\$9000) (Fig. 1). These costs were significantly higher than those of patients with diabetes only and none of the comorbidities (\$3365) (all $p$ values $<0.0001$ )

Ambulatory care accounted for the largest percentage of total costs across all groups (49-67\%, depending on the comorbidity profile) (Fig. 1). Notably, inpatient care accounted for roughly one-third of total spending among patients with dominant comorbidities and patients with both concordant and discordant conditions-a larger cost driver compared with other comorbidity groups (8-24\%). Prescriptions accounted for $10-20 \%$ of total health care costs, depending on the comorbidity profile. The parsimonious model that included demographic characteristics only yielded numerically similar cost estimates as the fully adjusted model and thus the results are not shown.

\section{Distribution of Health Care Expenditures by Comorbidity Profile}

Type 2 diabetes patients who had dominant comorbidities accounted for a disproportionately large share of total health care costs (Fig. 2). More than half of the overall costs (53\%) were attributable to individuals with dominant conditions, although they only represented $25 \%$ of the sample. Diabetes patients with both concordant and discordant comorbidities ( $24 \%$ of the sample) also accounted for a higher proportion $(27 \%)$ of total costs. In contrast, diabetes patients who had discordant comorbidities only ( $27 \%$ of the sample), concordant comorbidities only (7\% of the sample), or no comorbidities recorded in claims $(17 \%$ of the sample) accounted for a disproportionately small fraction of total costs in the population $(14 \%, 3 \%$, and $3 \%$, respectively).

\section{DISCUSSION}

In a large, privately insured population with newly diagnosed type 2 diabetes, we found that roughly a quarter of patients had only comorbidities unrelated to diabetes (e.g., pulmonary disorders and musculoskeletal diseases), a quarter had severe, coexisting medical conditions that may eclipse diabetes management (e.g., cancer and dementia), and a quarter had both diabetes-concordant and -discordant comorbidities; only $7 \%$ had concordant conditions that share care goals with diabetes and no other types of comorbidities. We also found that patients' health care utilization and costs varied substantially across comorbidity groups. In particular, diabetes patients with clinically dominant conditions accounted for a disproportionately large share of health care costs. Their average spending was almost twice as high 


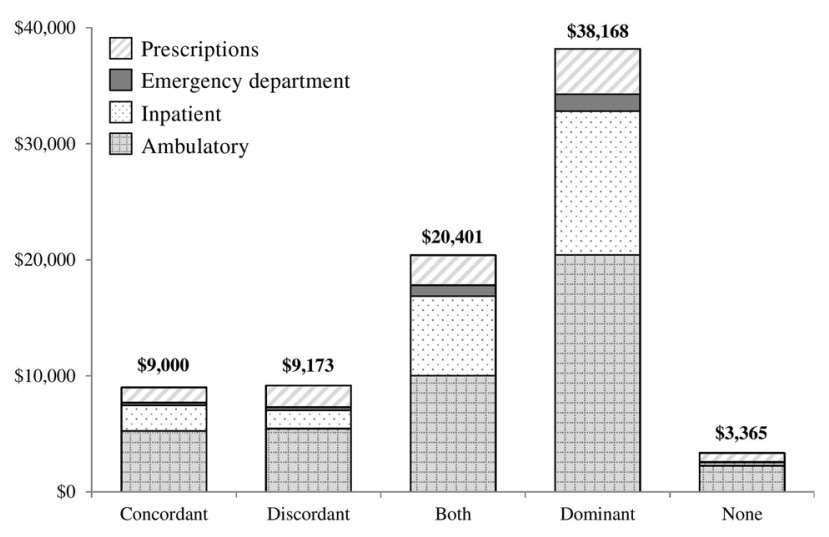

Fig. 1 Estimated mean health care costs by care component and by comorbidity group

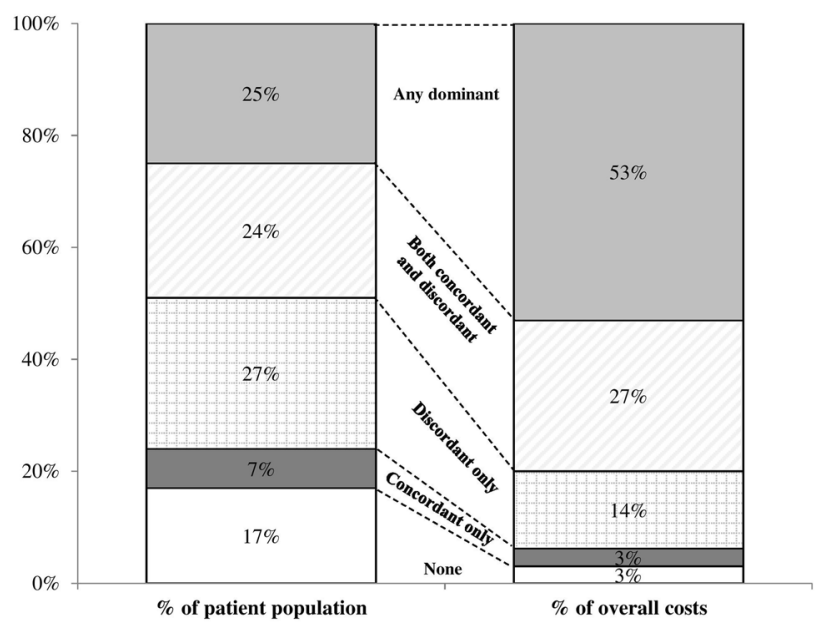

Fig. 2 Proportion of overall health care costs accounted by each comorbidity group

as patients with both concordant and discordant comorbidities, and more than four times as high as patients with concordant illnesses only or discordant illnesses only, even after adjusting for demographic characteristics, health insurance type, region, and prior utilization.

Differentiating the nature of comorbidities and their relationships to diabetes is critical to disease management $[1,2,22]$. Previous studies have documented that not only the count but also the type and combination of comorbidities may alter the priorities of diabetes care [1-12]. Some complex or severe comorbid illnesses may even dictate all other disease management plans, including diabetes [1-4]. For example, one analysis of the Diabetes Epidemiology Cohort (DEpiC) found that diabetes patients with clinically dominant comorbidities may be less likely to test their HbA1c and LDL-C regularly, visit a medical professional for diabetesrelated care, and meet glycemic and lipid management goals, compared with individuals with other types of comorbidities [4]. In an analysis of veterans with diabetes, one in three patients had serious or multiple medical or mental health problems that would increase the risks or decrease the benefits of intensive glycemic control [23]. Our findings further indicate that severely symptomatic conditions (e.g., dementia) or end-stage illnesses (e.g., end-stage renal disease) may drive health care resource use in the diabetes population more than other types of comorbidities, highlighting the 
substantial health care needs of diabetes patients with complex health status.

Despite the well-recognized comorbidity burden in patients with diabetes, clinical practice guidelines often do not explicitly address "comorbidity interrelatedness" [24], with few exceptions such as the 2012 joint consensus report by the American Diabetes Association and the American Geriatrics Society [25] and the 2018 American Diabetes Association Standards of Medical Care in diabetes for older adults [26], which provide guidance on treating diabetes in the context of geriatric conditions. Although studies have suggested aggressive management of metabolic syndromes and concordant conditions among diabetes patients [27], less attention has been paid to other types of comorbidities. Further, some concordant conditions, such as obesity and renal impairment, have been found to predict high-cost diabetes patients [28]. Although some patients may benefit from disease-specific interventions, for people with multimorbidity, coordinated services across multiple conditions are essential to maximize health care efficiency [29]. In our sample, few diabetes patients (7\%) had concordant conditions only, whereas the majority of patients with diabetes were faced with various co-existing health problems. Diabetes care management programs must address the comorbidity mix, treatment burden, and competing care demands, because managing individual health conditions in isolation may be ineffective and inefficient [22, 30-32]. In some cases, adherence to treatment guidelines for one disease may even adversely exacerbate another $[24,30]$.

In our sample, more than half of the total costs were concentrated on diabetes patients with clinically dominant conditions. Indeed, dominant comorbidity, such as dementia [33] and cancer [34], can make the management of other conditions, including diabetes, more difficult and expensive. Although dementia [35-39] and cancer [40-53] also may be associated with diabetes, these conditions are intentionally classified as dominant, rather than concordant, comorbidities in our analysis to be consistent with the Piette and Kerr framework. These conditions require special consideration because the complexity and seriousness of the disease often eclipse the management of other health problems, including diabetes [1]. In contrast, only $3 \%$ of total costs were attributable to diabetes patients with concordant comorbidities only. Better understanding the distribution of health care expenditures in the population is crucial because the information can help payers, providers, and policymakers assess the disease burden in different subgroups, which has implications for patient care $[54,55]$. As providers are facing increased pressure to control health care costs, one common strategy may be to target the specific subgroup responsible for a disproportionately large share of expenditures [56,57]. To that end, the Piette and Kerr framework may serve as a screening tool for identification of high-need, high-cost patients with diabetes and suggest targets for tailored interventions, such as intensive medication treatment $[58,59]$. A collaborative, multidisciplinary team approach, such as the Chronic Care Model, may be especially pertinent to managing multiple comorbidities as it has been shown to facilitate patient self-management and improve diabetes care quality [60-62].

As the economic burden of diabetes continues to rise, payers and providers, including accountable care organizations, need reliable methods to predict health care expenditures and identify patients with high-cost risk. Our findings suggest that explicit consideration of diabetes concordant, discordant, and dominant comorbidities as defined by the Piette and Kerr framework is important not only because this classification is clinically meaningful but because this approach segments patients into "actionable cohorts" [56] with distinctly different expenditure profiles. Appropriate risk adjustment based on patients' demographic characteristics, comorbidity burden, and other factors is essential for quality reporting and payfor-performance programs [63-65]. Additional research comparing performance of the Piette and Kerr classification methods and other diabetes-specific risk adjustment measures in expenditure prediction [66] would be useful in improving diabetes value-based payment models. 
Our analysis measured baseline comorbidities prior to the type 2 diabetes diagnosis. Possibly some concordant comorbidities may have not had ample time to develop. Concordant comorbidities that are nonetheless present in our data may be different from those that develop after diabetes diagnosis. It would be helpful for future research to characterize the temporal sequence of comorbidity and the corresponding cost impacts among patients with type 2 diabetes. Further analyses could extend the follow-up period and examine how the relationship between comorbidity type and cost impacts may change over time. A subsequent longitudinal analysis might consider how the Piette and Kerr framework can be used to identify diabetes patients with persistent (in addition to transient) high costs.

Several limitations in our study merit discussion. First, comorbidity burden may have been underestimated as a result of under-diagnosis and under-coding in administrative claims data. Second, the comorbidity measure we analyzed, though widely used and clinically relevant, does not allow us to determine the severity of a given condition, which may affect health care resource use. Although clinical values (such as serum creatinine levels) may reflect disease severity, these data were only available for a subset of patients in Optum Clinformatics ${ }^{\circledR}$ Data Mart and therefore not used in our analyses. Third, Optum Clinformatics ${ }^{\circledR}$ Data Mart includes participants in commercial insurance plans and Medicare Advantage plans. Future research is needed to validate our results in other populations, such as fee-for-service Medicare beneficiaries with type 2 diabetes. Fourth, our analysis pertained to patients newly diagnosed with type 2 diabetes. This approach reduces time-dependent biases between patients, such as differences in duration and severity of diabetes as well as survival time [67], which may have important impact on costs. Sensitivity analyses including all patients with prevalent diabetes showed similar results, however. Finally, claims data lack information on patient values and preferences for care, which strongly correlate with one's health care decisions $[31,68]$. Future research should explore how to incorporate weights that reflect individual preferences into comorbidity measures in order to help guide treatment priorities and align treatment plans with patients' health care goals $[1,31,60]$.

\section{CONCLUSIONS}

In applying the Piette and Kerr framework for understanding the impact of comorbidity on individuals with diabetes, we found that patients with different types of co-existing medical conditions had distinctly different health care expenditure profiles. Diabetes patients with both concordant and discordant conditions and with clinically dominant conditions incurred substantially higher health care costs than other diabetes patients and accounted for a disproportionately large share of spending. Our analyses shed light on how to best focus efforts on high-need, high-cost diabetes patients who may require tailored care management. Incorporating a clinically meaningful classification of comorbidities such as the Piette and Kerr framework into risk adjustment measures may help enhance the performance of value-based payment models in diabetes care.

\section{ACKNOWLEDGEMENTS}

Funding. This study was supported by research funding from Sanofi to Tufts Medical Center. Sanofi also provided funds to cover the article processing charges. All authors had full access to all of the data in this study and take complete responsibility for the integrity of the data and accuracy of the data analysis.

Authorship. All named authors meet the International Committee of Medical Journal Editors (ICMJE) criteria for authorship for this article, take responsibility for the integrity of the work as a whole, and have given their approval for this version to be published.

Disclosures. Fang Liz Zhou is an employee and a stock holder of Sanofi. The other authors Pei-Jung Lin and Elle Pope have no financial or 
any other kind of personal conflicts with this paper.

Compliance with Ethics Guidelines. The Tufts Medical Center/Tufts University Health Sciences IRB reviewed this study and determined that it is exempt from ethical approval. This article does not contain any studies with human participants or animals performed by any of the authors.

Data Availability. The datasets during and/ or analyzed during the current study are available from the corresponding author on reasonable request.

Open Access. This article is distributed under the terms of the Creative Commons Attribution-NonCommercial 4.0 International License (http://creativecommons.org/licenses/ by-nc/4.0/), which permits any noncommercial use, distribution, and reproduction in any medium, provided you give appropriate credit to the original author(s) and the source, provide a link to the Creative Commons license, and indicate if changes were made.

\section{REFERENCES}

1. Piette JD, Kerr EA. The impact of comorbid chronic conditions on diabetes care. Diabetes Care. 2006;29(3):725-31.

2. Kerr EA, Heisler M, Krein SL, et al. Beyond comorbidity counts: how do comorbidity type and severity influence diabetes patients' treatment priorities and self-management? J Gen Intern Med. 2007;22(12):1635-40.

3. Laiteerapong N, Huang ES, Chin MH. Prioritization of care in adults with diabetes and comorbidity. Ann N Y Acad Sci. 2011;1243:69-87.

4. Pentakota SR, Rajan M, Fincke BG, et al. Does diabetes care differ by type of chronic comorbidity? An evaluation of the Piette and Kerr framework. Diabetes Care. 2012;35(6):1285-92.

5. Lagu T, Weiner MG, Hollenbeak CS, et al. The impact of concordant and discordant conditions on the quality of care for hyperlipidemia. J Gen Intern Med. 2008;23(8):1208-13.
6. Fisher K, Griffith L, Gruneir A, et al. Comorbidity and its relationship with health service use and cost in community-living older adults with diabetes: a population-based study in Ontario, Canada. Diabetes Res Clin Pract. 2016;122:113-23.

7. Lin PJ, Kent DM, Winn A, Cohen JT, Neumann PJ. Multiple chronic conditions in type 2 diabetes mellitus: prevalence and consequences. Am J Manag Care. 2015;21(1):e23-34.

8. Li R, Bilik D, Brown MB, et al. Medical costs associated with type 2 diabetes complications and comorbidities. Am J Manag Care. 2013;19(5):421-30.

9. Krein SL, Hofer TP, Holleman R, Piette JD, Klamerus ML, Kerr EA. More than a pain in the neck: how discussing chronic pain affects hypertension medication intensification. $\mathrm{J}$ Gen Intern Med. 2009;24(8):911-6.

10. Magnan EM, Palta M, Johnson HM, Bartels CM, Schumacher JR, Smith MA. The impact of a patient's concordant and discordant chronic conditions on diabetes care quality measures. J Diabetes Complicat. 2015;29(2):288-94.

11. Vitry AI, Roughead EE, Preiss AK, et al. Influence of comorbidities on therapeutic progression of diabetes treatment in Australian veterans: a cohort study. PLoS One. 2010;5(11):e14024.

12. Woodard LD, Urech $\mathrm{T}$, Landrum CR, Wang $\mathrm{D}$, Petersen LA. Impact of comorbidity type on measures of quality for diabetes care. Med Care. 2011;49(6):605-10.

13. Parchman ML, Pugh JA, Romero RL, Bowers KW. Competing demands or clinical inertia: the case of elevated glycosylated hemoglobin. Anna Fam Med. 2007;5(3):196-201.

14. Sales AE, Tipton EF, Levine DA, et al. Are co-morbidities associated with guideline adherence? The MI-Plus study of Medicare patients. J Gen Intern Med. 2009;24(11):1205-10.

15. American Diabetes Association. Economic costs of diabetes in the US in 2017. Diabetes Care. 2018;41(5):917-28.

16. Egede LE, Bishu KG, Walker RJ, Dismuke CE. Impact of diagnosed depression on healthcare costs in adults with and without diabetes: United States, 2004-2011. J Affect Disord. 2016;195:119-26.

17. Nichols GA, Brown JB. The impact of cardiovascular disease on medical care costs in subjects with and without type 2 diabetes. Diabetes Care. 2002;25(3):482-6. 
18. Gilmer TP, O'Connor PJ, Rush WA, et al. Predictors of health care costs in adults with diabetes. Diabetes Care. 2005;28(1):59-64.

19. McCarthy D, Ryan J, Klein S. Models of care for highneed, high-cost patients: an evidence synthesis. New York: The Commonwealth Fund Issue Brief; 2015.

20. Basu A, Rathouz PJ. Estimating marginal and incremental effects on health outcomes using flexible link and variance function models. Biostatistics (Oxf Engl). 2005;6(1):93-109.

21. Smith VA, Maciejewski ML, Olsen MK. Modeling semicontinuous longitudinal expenditures: a practical guide. Health Serv Res. 2018;53(S1):3125-47.

22. Valderas JM, Starfield B, Sibbald B, Salisbury C, Roland M. Defining comorbidity: implications for understanding health and health services. Ann Fam Med. 2009;7(4):357-63.

23. Pogach LM, Tiwari A, Maney M, Rajan M, Miller DR, Aron D. Should mitigating comorbidities be considered in assessing healthcare plan performance in achieving optimal glycemic control? Am J Manag Care. 2007;13(3):133-40.

24. Zulman DM, Asch SM, Martins SB, Kerr EA, Hoffman BB, Goldstein MK. Quality of care for patients with multiple chronic conditions: the role of comorbidity interrelatedness. J Gen Intern Med. 2014;29(3):529-37.

25. Kirkman MS, Briscoe VJ, Clark N, et al. Diabetes in older adults: a consensus report. J Am Geriatr Soc. 2012;60(12):2342-56.

26. American Diabetes Association. 11. Older adults: standards of medical care in diabetes-2018. Diabetes Care. 2018;41(Suppl 1):S119-215.

27. Hoerger TJ, Ahmann AJ. The impact of diabetes and associated cardiometabolic risk factors on members: strategies for optimizing outcomes. J Manag Care Pharm. 2008;14(1 Suppl C):S2-14 (quiz 5-6).

28. Meyers JL, Parasuraman S, Bell KF, Graham JP, Candrilli SD. The high-cost, type 2 diabetes mellitus patient: an analysis of managed care administrative data. Arch Public Health. 2014;72(1):6.

29. Zulman DM, Pal Chee C, Wagner TH, et al. Multimorbidity and healthcare utilisation among highcost patients in the US Veterans Affairs Health Care System. BMJ Open. 2015;5(4):e007771.

30. Boyd CM, Darer J, Boult C, Fried LP, Boult L, Wu AW. Clinical practice guidelines and quality of care for older patients with multiple comorbid diseases: implications for pay for performance. JAMA. $2005 ; 294(6): 716-24$
31. Durso SC. Using clinical guidelines designed for older adults with diabetes mellitus and complex health status. JAMA. 2006;295(16):1935-40.

32. Tinetti ME, McAvay GJ, Chang SS, et al. Contribution of multiple chronic conditions to universal health outcomes. J Am Geriatr Soc. 2011;59(9):1686-91.

33. Lin PJ, Fillit HM, Cohen JT, Neumann PJ. Potentially avoidable hospitalizations among Medicare beneficiaries with Alzheimers disease and related disorders. Alzheimer's Dement. 2013;9(1):30-8.

34. Guy GP Jr, Yabroff KR, Ekwueme DU, et al. Healthcare expenditure burden among non-elderly cancer survivors, 2008-2012. Am J Prev Med. 2015;49(6 Suppl 5):S489-97.

35. Strachan MW, Reynolds RM, Marioni RE, Price JF. Cognitive function, dementia and type 2 diabetes mellitus in the elderly. Nat Rev Endocrinol. 2011;7(2):108-14.

36. Exalto LG, Whitmer RA, Kappele LJ, Biessels GJ. An update on type 2 diabetes, vascular dementia and Alzheimer's disease. Exp Gerontol. 2012;47(11):858-64.

37. Biessels GJ, Strachan MW, Visseren FL, Kappelle LJ, Whitmer RA. Dementia and cognitive decline in type 2 diabetes and prediabetic stages: towards targeted interventions. Lancet Diabetes Endocrinol. 2014;2(3):246-55.

38. Jayaraman A, Pike CJ. Alzheimer's disease and type 2 diabetes: multiple mechanisms contribute to interactions. Curr Diab Rep. 2014;14(4):476.

39. Ninomiya T. Diabetes mellitus and dementia. Curr Diab Rep. 2014;14(5):487.

40. Giovannucci E, Harlan DM, Archer MC, et al. Diabetes and cancer: a consensus report. Diabetes Care. 2010;33(7):1674-85.

41. Crujeiras AB, Diaz-Lagares A, Carreira MC, Amil M, Casanueva FF. Oxidative stress associated to dysfunctional adipose tissue: a potential link between obesity, type 2 diabetes mellitus and breast cancer. Free Radical Res. 2013;47(4):243-56.

42. McAuliffe JC, Christein JD. Type 2 diabetes mellitus and pancreatic cancer. Surg Clin North Am. 2013;93(3):619-27.

43. Carstensen B, Jorgensen ME, Friis S. The epidemiology of diabetes and cancer. Curr Diab Rep 2014;14(10):535.

44. Garg SK, Maurer H, Reed K, Selagamsetty R. Diabetes and cancer: two diseases with obesity as a 
common risk factor. Diabetes Obes Metab. 2014;16(2):97-110.

45. Onitilo AA, Stankowski RV, Berg RL, et al. Type 2 diabetes mellitus, glycemic control, and cancer risk. Eur J Cancer Prev. 2014;23(2):134-40.

46. Onitilo AA, Stankowski RV, Berg RL, Engel JM, Glurich I, Williams GM, et al. Breast cancer incidence before and after diagnosis of type 2 diabetes mellitus in women: increased risk in the prediabetes phase. Eur J Cancer Prev. 2014;23(2):76-83.

47. Szablewski L. Diabetes mellitus: influences on cancer risk. Diabetes Metab Res Rev. 2014;30(7):543-53.

48. Zelenko Z, Gallagher EJ. Diabetes and cancer. Endocrinol Metab Clin North Am. 2014;43(1):167-85.

49. Guraya SY. Association of type 2 diabetes mellitus and the risk of colorectal cancer: a meta-analysis and systematic review. World J Gastroenterol. 2015;21(19):6026-31.

50. Joung $\mathrm{KH}$, Jeong JW, Ku BJ. The association between type 2 diabetes mellitus and women cancer: the epidemiological evidences and putative mechanisms. Biomed Res Int. 2015;2015:920618.

51. Liu X, Hemminki K, Forsti A, Sundquist K, Sundquist J, Ji J. Cancer risk in patients with type 2 diabetes mellitus and their relatives. Int $\mathrm{J}$ Cancer. 2015;137(4):903-10.

52. Valent F. Diabetes mellitus and cancer of the digestive organs: an Italian population-based cohort study. J. Diabetes Complicat. 2015;29(8):1056-61.

53. Zhou Y, Zhang X, Gu C, Xia J. Diabetes mellitus is associated with breast cancer: systematic review, meta-analysis, and in silico reproduction. Panminerva Med. 2015;57(3):101-8.

54. Riley GF. Long-term trends in the concentration of Medicare spending. Health Aff (Millwood). 2007;26(3):808-16.

55. Vogeli C, Shields AE, Lee TA, et al. Multiple chronic conditions: prevalence, health consequences, and implications for quality, care management, and costs. J Gen Intern Med. 2007;22(Suppl 3):391-5.

56. Joynt KE, Figueroa JF, Beaulieu N, Wild RC, Orav EJ, Jha AK. Segmenting high-cost Medicare patients into potentially actionable cohorts. Healthc (Amst). 2017;5(1-2):62-7.

57. Lieberman SM, Lee J, Anderson T, Crippen DL. Reducing the growth of Medicare spending: geographic versus patient-based strategies. Health Aff (Millwood). 2003;Suppl Web Exclusives:W3603-13.

58. CDC Diabetes Cost-effectiveness Group. Cost-effectiveness of intensive glycemic control, intensified hypertension control, and serum cholesterol level reduction for type 2 diabetes. JAMA. 2002;287(19):2542-51.

59. Palmer AJ, Annemans L, Roze S, et al. Cost-effectiveness of early irbesartan treatment versus control (standard antihypertensive medications excluding ACE inhibitors, other angiotensin-2 receptor antagonists, and dihydropyridine calcium channel blockers) or late irbesartan treatment in patients with type 2 diabetes, hypertension, and renal disease. Diabetes Care. 2004;27(8):1897-903.

60. American Diabetes Association. Strategies for improving care. Diabetes Care. 2016;39(Suppl 1):S6-12.

61. Coleman K, Austin BT, Brach C, Wagner EH. Evidence on the chronic care model in the new millennium. Health Aff (Millwood). 2009;28(1):75-85.

62. Stellefson M, Dipnarine K, Stopka C. The chronic care model and diabetes management in US primary care settings: a systematic review. Prev Chronic Dis. 2013;10:E26.

63. Spatz ES, Lipska KJ, Dai Y, et al. Risk-standardized acute admission rates among patients with diabetes and heart failure as a measure of quality of accountable care organizations: rationale, methods, and early results. Med Care. 2016;54(5):528-37.

64. Abraham JM, Marmor S, Knutson D, Zeglin J, Virnig B. Variation in diabetes care quality among Medicare Advantage plans: understanding the role of case mix. Am J Med Qual. 2012;27(5):377-82.

65. Casalino LP, Elster A, Eisenberg A, Lewis E, Montgomery J, Ramos D. Will pay-for-performance and quality reporting affect health care disparities? Health Aff (Millwood). 2007;26(3):w405-14.

66. Maciejewski ML, Liu CF, Fihn SD. Performance of comorbidity, risk adjustment, and functional status measures in expenditure prediction for patients with diabetes. Diabetes Care. 2009;32(1):75-80.

67. Tran J, Norton R, Conrad N, et al. Patterns and temporal trends of comorbidity among adult patients with incident cardiovascular disease in the UK between 2000 and 2014: a population-based cohort study. PLoS Med. 2018;15(3):e1002513.

68. Chin MH, Drum ML, Jin L, Shook ME, Huang ES, Meltzer DO. Variation in treatment preferences and care goals among older patients with diabetes and their physicians. Med Care. 2008;46(3):275-86. 